\title{
Evaluating Tornado Casualty Rates in the United States
}

\author{
Tyler Fricker* \\ Department of Geography, Texas AछM University, College Station, Texas, USA
}

\begin{abstract}
Tornadoes account for nearly one fifth of all natural hazard fatalities in the United States, yet there exist no general estimates of casualty rates across the country. Here tornado casualty rates are estimated for all casualty-producing tornadoes over the period 1995-2016 using tornado level information related to the population and total housing units within each damage path. The 22-year United States per-capita casualty rate is $2.3 \%$, while the 22-year United States per-housing unit casualty rate is $5.4 \%$. Injury and fatality rates are also estimated over the same period. The 22-year United States per-capita fatality rate is $.15 \%$ and the per-capita injury rate is $2.1 \%$. The per-housing unit fatality rate is $.36 \%$ and the per-housing unit injury rate is $5.1 \%$. Casualty rates are further examined through subsets of Enhanced Fujita rating, state boundaries, and county boundaries. When used in conjunction with estimates of future changes in tornado behavior and population growth, these casualty rates can help predict tornado casualty events in communities throughout the United States.
\end{abstract}

Keywords: Tornadoes, Casualties, Vulnerability

\section{Introduction}

Tornadoes are violently rotating columns of wind that pose a threat to life and property. They account for nearly one fifth of all natural hazard fatalities in the United States (U.S.) alone (National Oceanic and Atmospheric Administration, 2015). While the destruction of a community's built environment can severely disrupt economic productivity, perhaps no impact of a tornado is felt deeper than the resulting casualties - injuries or deaths.

Previous research has largely focused on the number or location of tornado casualtiesoften tornado fatalities (Grazulis, 1990; Hammer and Schmidlin, 2000; Ashley, 2007; Fricker et al., 2017b). For example, Grazulis (1990) provides a historical collection of significant and killer tornado reports, which highlights changes in the rate of tornado fatalities over time (Brooks and Doswell, 2002). Hammer and Schmidlin (2000) investigate vehicle-associated deaths in tornadoes over the period 1900-1998 and find that vehicle-occupant deaths were consistent in relative proportion to all location-specific deaths from 1959-1979, but decreased significantly between 1980-1989. Arguably the most comprehensive analysis of tornado fatalities is seen in Ashley (2007), where spatial and temporal consideration are given to all tornado fatalities between 1880-2005. Results from Ashley (2007) show a larger number of

*email:tfricker@tamu.edu 
fatalities occurring in the lower-Arkansas, Tennessee, and Mississippi River valleys of the southeastern United States. These results are further supported by Fricker et al. (2017b) who use a dasymetric method to map tornado casualties - injuries and fatalities - over the period 1955-2016.

Factors that influence the number of tornado casualties are well known. Wind energy and population density explain a large portion of tornado casualty rates (Ashley et al., 2014; Fricker et al., 2017a; Elsner et al., 2018a), with socioeconomic and demographic factors also playing a role (Simmons and Sutter, 2005, 2008, 2009; Donner, 2007; Dixon and Moore, 2012; Lim et al., 2017; Strader and Ashley, 2018). For example, Simmons and Sutter (2005, 2008, 2009) find that the number of tornado casualties increases with an increase in the percentage of mobile homes in an area. In addition, Kilijanek and Drabek (1979), Cutter et al. (2000), Dixon and Moore (2012), and Donner et al. (2012) find that an increase in the number of elderly individuals (age 65 and older) is likely to result in an increase in the number of tornado - or more generally, natural hazard - casualties.

Less understood are general casualty rates - that is, on average, how many injuries and deaths occur per person or per housing unit in casualty-producing tornadoes. Put another way, how many injuries and deaths occur in casualty-producing tornadoes given an estimated number of people and housing units within the tornado damage path. Previous research (Eidson et al., 1990; Legates and Biddle, 1999; Daley et al., 2005; Brooks et al., 2008; Corfidi et al., 2010; Kuligowski et al., 2013) has focused on case studies to gain insight into the number or rate of tornado injuries and fatalities. For instance, Brooks et al. (2008) synthesized results from previous studies to show that, historically, tornado fatality rates have ranged from 0.1\% within the 3 May, 1999 Oklahoma City, Oklahoma EF5 tornado (Daley et al., 2005) to $1.0 \%$ in the 8 April, 1998 Birmingham, Alabama EF4 tornado (Legates and Biddle, 1999). Regarding injuries, Eidson et al. (1990), Brown et al. (2002), and Corfidi et al. (2010) find a ratio between the number of tornado fatalities and tornado injuries to be approximately 16, 15, and 17 injuries for each fatality, respectively, while Kuligowski et al. (2013) finds a ratio of approximately 6 injuries for each fatality.

Predicting scenarios of occurrence is one way to estimate the impact future tornadoes can have on society. These predictions are typically made through Monte Carlo simulations (Meyer et al., 2002; Daneshvaran and Morden, 2007; Strader et al., 2017) and incorporate potential changes to physical or social environments. For example, Strader et al. (2017) use the Tornado Impact Monte Carlo (TorMC) model to simulate tornado events and estimate the impact or cost on the underlying surface. Using future projections of the dispersal and number of housing units (the Spatially Explicit Regional Growth Model and the Integrated Climate and Land Use Scenarios), they find a potential threefold increase in median annual tornado impact - in housing units - when accounting for changes in risk and exposure over the period 2010-2100. More recently, Fan and Pang (2019) use a stochastic track model to generate genesis locations of tornadoes and calculate annual spawn frequencies by Enhanced Fujita (EF) Scale rating for four major U.S. cities - Indianapolis, Indiana, Birmingham, Alabama, Oklahoma City, Oklahoma, and Des Moines, Iowa. They find the highest significant tornado $(\mathrm{EF} 2+)$ annual spawn frequency in Birmingham, Alabama, indicating high future tornado risk across portions of the southeastern United States.

Reconstructing past events is another way to estimate the impact future tornadoes can have on society. Using historical tornado track data and transposing it onto modern land- 
scapes makes it possible to identify worst-case scenarios of tornado destruction (Wurman et al., 2007; Hall and Ashley, 2008; Ashley et al., 2014; Elsner et al., 2018c; Antonescu et al., 2018). For example, Elsner et al. (2018c) overlay historical tornado paths onto fine-scale Florida property value data and find a $1 \%$ chance that the annual loss will exceed $\$ 430$ million and $0.1 \%$ chance that the annual loss will exceed $\$ 1$ billion. Similarly, Antonescu et al. (2018) rearrange tornadoes from the historical 24-25 June, 1967 European outbreak to estimate what the event might look like if it occurred today. Using fatality rates ranging from 0.1\% to 1.0\% (Legates and Biddle, 1999; Daley et al., 2005; Brooks et al., 2008), and injury rates of 15 injuries per fatality, they find the same outbreak - were it to happen today - could result in the destruction of over 24,000 buildings, and produce 25-2,580 injuries, as well as 17-172 fatalities.

These future predictions and worst-case scenarios (Clarke, 2005) signal the importance of understanding societal risk and vulnerability to the tornado hazard. While relying on case-study estimates of tornado injuries and fatalities is useful for predicting the destructive potential of tornadoes on the same or a similar location, they do little to provide insight into what to expect in a casualty-producing tornado at any location across the country - or the world. In response, here tornado casualty rate estimates are made for all casualty-producing tornadoes impacting the United States between 1995-2016. These rates exist as a function of population (per-capita) and households (per-housing unit) and apply generally across space - or more specifically, the contiguous United States. Through a spatial and temporal examination of tornado casualty rates, this work stands to provide a foundation for future research concerning the prediction of what changes in physical or social environments may mean to the rate of tornado casualties.

\section{Data and Methods}

\subsection{Historical Tornado Reports}

Tornado reports are obtained from the U.S. Storm Prediction Center (SPC). The SPC database is the most complete and detailed tornado database in the world and includes information related to the spatial location and dimensions of the damage path, the initiation point (latitude and longitude), date, and maximum damage rating from 0 to 5 (Fujita (F) Scale prior to February 2007 and EF Scale thereafter). Important for this work, it also includes the number of casualties - fatalities and injuries. "Casualty", as defined by the National Weather Service (NWS) Storm Data, refers to either human death or injury as a direct consequence of a tornado.

Tornado reports in the database are compiled initially by local NWS offices and reviewed by the National Center for Environmental Information (Verbout et al., 2006) before entering the database. The SPC database is available in a shapefile format (https://www .spc.noaa. gov/gis/svrgis/) with each tornado represented as a straight-line track between the start and end locations or an initiation point. Here all casualty-producing tornadoes - tornadoes that produced one injury or death - in the database over the period 1995-2016 are considered. The start year coincides with the period of record where maximum path width was adopted by the NWS and represents the start of a period of record consistent in tabulation methods. 


\subsection{Population and Housing Data}

Population and housing data are obtained from the United States Census Bureau and the American Community Survey (ACS). The boundary shapefiles are obtained from the topologically integrated geographic encoding and referencing (TIGER) database. The ACS is a nationwide survey that includes demographic, social, economic, and housing information by year at the state, county, tract, block group, and block level.

Here, population and housing data are evaluated at the Census tract level so as to be large enough to include the entire region of interest and small enough to provide more detailed information than other geographies. The study includes information from the 1990 and 2000 Census, as well as the 2010 ACS five-year estimates. Differences in the quality of data exist between the 1990 and 2000 Census and the 2010 ACS. This is because of a difference in data collection strategy, which resulted in approximately 19 million households being sampled in the 2000 Census and approximately 3.54 million households in the ACS (Folch et al., 2016).

While there are a number of challenges associated with using ACS data (Macdonald, 2006; Salvo and Lobo, 2006; Bazuin and Fraser, 2013; Spielman et al., 2014; Folch et al., 2016), reliable estimates of socioeconomic or demographic variables are rooted in the margins of error (MOE) of the ACS. For the two variables of interest (total population and total housing units), the average associated MOE are below 10\% with an interquartile range between $6 \%$ and $10 \%$ for total population and between $3 \%$ and $6 \%$ for total housing units (Fricker, 2020).

\subsection{Tornado Model and Dasymetric Method}

Tornado paths are made using a buffer on the straight line track in accordance with recorded maximum path width. Estimates of total population and housing units are computed for each tornado, using a dasymetric procedure similar to that used in Fricker et al. (2017b) and further explained in Fricker (2020). The procedure requires two sets of volumetric data: the spatial path of the tornado and the demographic data and its areal representation as Census tracts.

The dasymetric calculations are made using weighted estimates of population and housing units for each fraction of the tornado path as a ratio of the fraction of the tornado path that occurs within a Census tract and the total area of the Census tract. When added together, the weighted estimates result in a total estimate of population and housing units for the entire tornado path. Final estimates are calculated through linear interpolation based on the year of occurrence. Tornadoes on or after 2010 are assigned estimates of the year 2010.

The result of the implementation of the dasymetric method is a data set similar in structure to the SPC database, with additional columns present, including total population and total housing units. Given the nature of the tornado model used here, it is reasonable to assume potential error in the estimates due to the use of a straight line track buffered in accordance with recorded maximum width. However, as Fricker (2020) shows, the percent error between modeled damage path estimates and actual damage path estimates from the NWS Damage Assessment Toolkit (https ://apps . dat.noaa.gov/stormdamage/damageviewer/) is less than $5 \%$ for both total population and total housing units, indicating the methodology is quite useful.

With estimates of total population and total housing units in a data set that includes information on recorded tornado casualties (injuries and fatalities), location, date, time, and maximum damage rating, it is possible to subset tornadoes by their characteristics. For 
example, when subset by maximum damage rating (EF scale), estimates can be made for total population and total housing units (Table 1). When leveraged with information on the number of tornadoes and the number of tornado casualties, per-capita and per-housing unit casualty rates can be estimated.

Table 1: Estimates of total population and total housing units by EF-rating

\begin{tabular}{lcccc}
\hline EF-rating & Number of Tornadoes & Number of Casualties & Total Population & Total Housing Units \\
\hline 0 & 177 & 354 & 4432 & 2071 \\
1 & 749 & 2299 & 157922 & 67837 \\
2 & 753 & 4888 & 322071 & 133843 \\
3 & 392 & 7933 & 356699 & 152270 \\
4 & 116 & 7187 & 219554 & 95554 \\
5 & 14 & 3298 & 68782 & 28204 \\
\hline
\end{tabular}

\section{Results}

\subsection{General Casualty Rates}

General casualty rates are calculated for every U.S. casualty-producing tornado over the period 1995-2016. For the 22-year study period, there were 2,201 casualty-producing tornadoes that resulted in 25,959 casualties. The sum of the estimated population within the path of these tornadoes is 1,129,460 and the sum of the estimated housing units within the path of these tornadoes is 479,778 , which corresponds to a per-capita casualty rate of $2.3 \%$ and a per-housing unit casualty rate of $5.4 \%$ (Table 2 ).

General casualty rates can be further broken down into injury and fatality rates. For the 22-year study period, there were 472 killer tornadoes - those that resulted in one or more fatalities-producing 1,730 fatalities. There were also 2,121 injury-producing tornadoesthose that resulted in one or more injuries - producing 24,229 injuries. This corresponds to a per-capita fatality rate of $.15 \%$ and a per-capita injury rate of $2.1 \%$ (Table 2). In addition, this corresponds to a per-housing unit fatality rate of $.36 \%$ and a per-housing unit injury rate of $5.1 \%$ (Table 2). When considering the relationship between injuries and fatalities, the ratio between the number of tornado fatalities and tornado injuries for the set of casualtyproducing tornadoes is 14 injuries for each fatality, consistent with previous research (Eidson et al., 1990; Brown et al., 2002; Corfidi et al., 2010).

Table 2: Casualty rates, fatality rates, and injury rates in the United States over the period 1995-2016.

\begin{tabular}{lccc}
\hline Level & Casualty Rate & Fatality Rate & Injury Rate \\
\hline Per-Capita & .0229 & .0015 & .0214 \\
Per-Housing Unit & .0541 & .0036 & .0505 \\
\hline
\end{tabular}

\subsection{Casualty Rates by EF-Rating}

Owing to the quality of the historical tornado record, casualty rates can also be evaluated by maximum damage rating (EF-rating). The impact EF-rating has on the number of tornado casualties is well known, with higher maximum damage ratings resulting in more 
casualties (Simmons and Sutter, 2005, 2008, 2009), due, in part, to stronger winds and higher associated energy or power (Fricker et al., 2014; Fricker and Elsner, 2015). Unsurprisingly, casualty rates increase with EF-rating, with one exception: EF0 tornadoes have a higher casualty and injury rate than every other maximum damage rating. This result is likely due to a small number problem, with EF0 tornadoes impacting a much smaller population (4,432 people) and total housing units (2,071 housing units) than any other EF-rating. In fact, the next closest total impacted population is EF5 tornadoes with 68,782 people and 28,204 housing units. Additionally, EF0 tornadoes have historically been used as an unknown EF-rating (Doswell et al., 2009), which may explain the relatively high number of EF0 casualty-producing tornadoes and casualty rates seen in this work.

For the set of all casualty-producing tornadoes, the per-capita casualty rate by EFrating - excluding EF0 rates - ranges from a low of 1.5\% (EF1 and EF2) to a high of 4.8\% (EF5) (Table 3). In addition, the per-capita fatality rate by EF-rating - excluding EF0 rates - ranges from a low of .05\% (EF1) to a high of .60\% (EF5), while the per-capita injury rate by EF-rating - excluding EF0 rates - ranges from a low of 1.4\% (EF1) to a high of $4.2 \%$ (EF5). When considering the relationship between injuries and fatalities, the ratio between the number of tornado fatalities and tornado injuries by EF-rating ranges from a high of 43 injuries for each fatality (EF0) to a low of 7 injuries for each fatality (EF5).

Table 3: Per-capita casualty rates, fatality rates, and injury rates by EF-rating

\begin{tabular}{lccc}
\hline EF-rating & Casualty Rate & Fatality Rate & Injury Rate \\
\hline 0 & .0799 & .0018 & .0781 \\
1 & .0146 & .0005 & .0141 \\
2 & .0152 & .0007 & .0145 \\
3 & .0222 & .0015 & .0207 \\
4 & .0327 & .0021 & .0307 \\
5 & .0479 & .0062 & .0417 \\
\hline
\end{tabular}

For the same set of all casualty-producing tornadoes, the per-housing unit casualty rate by EF-rating - excluding EF0 rates - ranges from a low of 3.3\% (EF1) to a high of $12 \%$ (EF5) (Table 4). Additionally, the per-housing unit fatality rate by EF-rating - excluding EF0 rates - ranges from a low of .11\% (EF1) to a high of 1.5\% (EF5), while the per-housing unit injury rate by EF-rating - excluding EF0 rates - ranges from a low of $3.2 \%$ (EF1) to a high of 10\% (EF5).

Table 4: Per-housing unit casualty rates, fatality rates, and injury rates by EF-rating

\begin{tabular}{lccc}
\hline EF-rating & Casualty Rate & Fatality Rate & Injury Rate \\
\hline 0 & .1709 & .0039 & .1671 \\
1 & .0339 & .0012 & .0327 \\
2 & .0365 & .0016 & .0349 \\
3 & .0521 & .0035 & .0486 \\
4 & .0752 & .0048 & .0704 \\
5 & .1169 & .0153 & .1016 \\
\hline
\end{tabular}




\subsection{State-Level Casualty Rates}

Because the historical tornado record includes information on the spatial location and dimensions of the damage path, estimated casualty rates can move beyond aspatial measurements into spatial ones. When subset by state, per-capita casualty rates for the set of casualty-producing tornadoes range from a low of .15\% in Michigan to a high of $100 \%$ in Delaware and New Jersey (Fig. 1). The per-capita casualty rates in Delaware and New Jersey highlight some limitations in the historical record, relative to the spatial path of each tornado. In fact, the 4 casualty-producing tornadoes that impacted these two states exist as a buffered track with total path areas less than .30 square kilometers, which is far smaller than the average total path area of a casualty-producing tornado at 7.9 square kilometers. When these two states are removed, the next highest casualty rate is $40 \%$ in Utah.

Figure 1: (A) Per-capita state-level casualty rates for the contiguous United States, and (B) per-capita state-level casualty rates for states with 10 or more casualty-producing tornadoes. The casualty rates exist as the number of casualties per person.

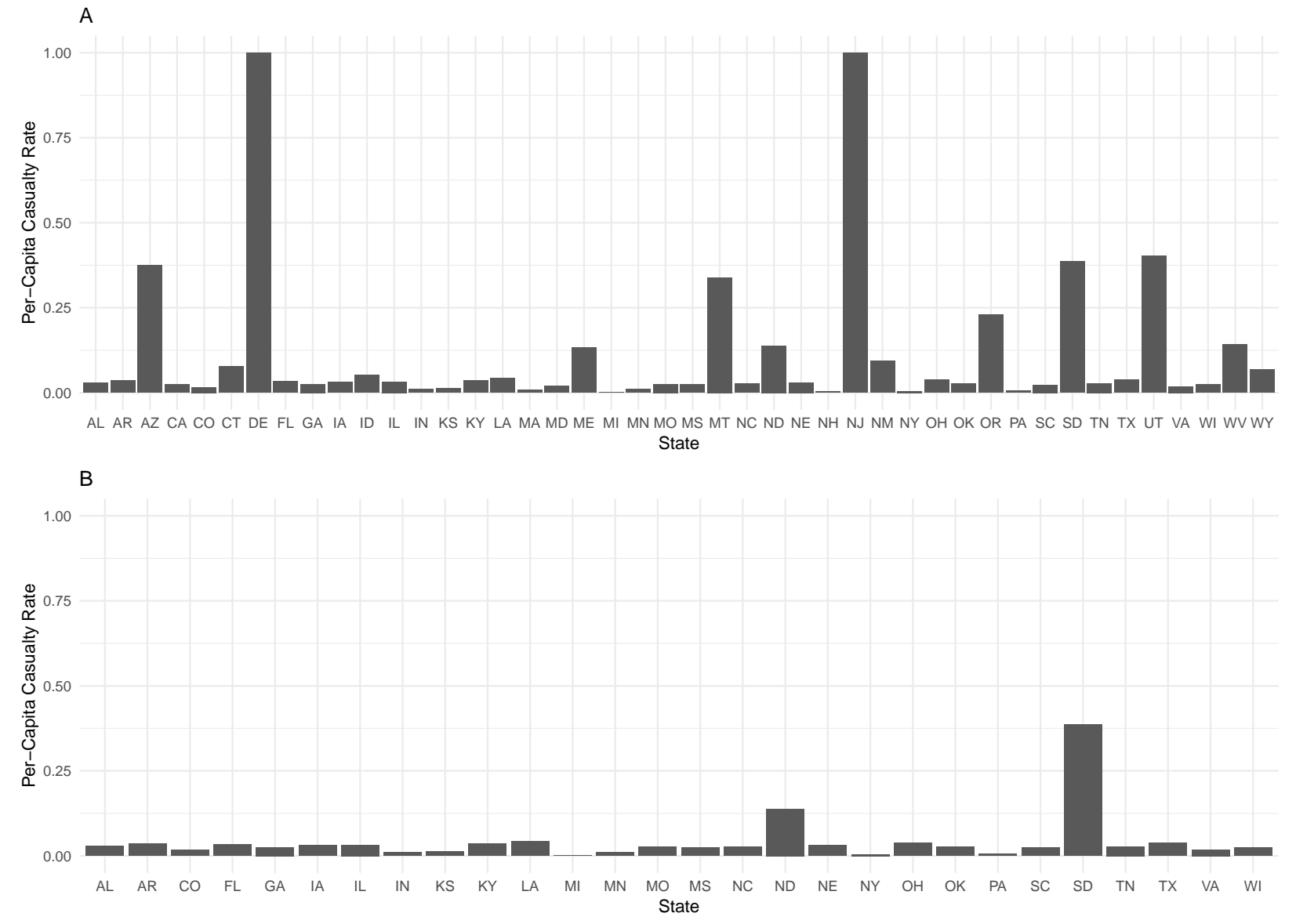

To create a more detailed picture of state-level per-capita casualty rates, only those states with 10 or more casualty-producing tornadoes are considered (Fig. 1). Of the group of states with a history of many casualty-producing tornadoes, per-capita casualty rates range from a low of $.15 \%$ in Michigan to a high of $38 \%$ in South Dakota. There appears to be a 
pattern of high per-capita casualty rates for states in the northern Great Plains, Midwest, and Southeast. Indeed, nine of the top ten states with the highest casualty rates (South Dakota, North Dakota, Louisiana, Ohio, Arkansas, Kentucky, Florida, Illinois, and Iowa) exist in these regions of the United States.

State-level per-capita injury and fatality rates follow a similar structure to state-level casualty rates. For the set of all casualty-producing tornadoes, the per-capita fatality rate by state ranges from a low of $0 \%$ in eight states (California, Idaho, Connecticut, Maine, West Virginia, Oregon, Arizona, and Delaware) to a high of $43 \%$ in New Jersey. The per-capita injury rate by state ranges from a low of $.15 \%$ in Michigan to a high of $100 \%$ in Delaware and New Jersey. When considering the set of states with 10 or more casualty-producing tornadoes, per-capita fatality rates drop to a high of $1.1 \%$ in South Dakota, while per-capita injury rates drop to a high of $37 \%$ in South Dakota.

When subset by state, per-housing unit casualty rates for the same set of casualty producing tornadoes range from a low of .38\% in Michigan to a high of of $100 \%$ in Delaware and New Jersey (Fig. 2) - again likely due to the small estimated damage path area of the casualty-producing tornadoes impacting those states. Of the same group of states with a history of many casualty-producing tornadoes, per-housing unit casualty rates range from a low of .38\% in Michigan to a high of $90 \%$ in South Dakota. In addition, the per-housing unit fatality rate by state ranges from a low of $0 \%$ in the same eight states to a high of $47 \%$ in New Jersey. The per-housing unit injury rate by state ranges from a low of .36\% in Michigan to $100 \%$ in Delaware and New Jersey. When considering only those states with 10 or more casualty-producing tornadoes, the per-housing unit fatality rates drop to a high of $26 \%$ and the per-housing unit injury rate drops to a high of $87 \%$, both in South Dakota.

Though the relative order of casualty rates by state do not change much between percapita and per-housing unit estimates, the magnitude of the casualty rates do. For example, while the per-capita casualty rate of the state of South Dakota is 39\%, the per-housing unit casualty rate of the same state is $90 \%$. Similarly, while the per-capita casualty rate of Montana is $34 \%$, the per-housing unit casualty rate is $65 \%$. One reason for this difference is likely due, in part, to the relationship between population and housing units in rural states (e.g. North Dakota and South Dakota), where older individuals live in aging and low quality housing. Another reason is likely due to the small number of total housing units impacted by casualty-producing tornadoes - relative to the number of people - in states with high casualty rates.

\subsection{County-Level Casualty Rates}

Overlaying the spatial location and dimensions of tornado damage paths onto U.S. counties allows for an estimation of county-level casualty rates. When tornadoes are subset by the counties they intersect (1401 total counties), per-capita casualty rates for the set of all casualty-producing tornadoes range from a low of .01\% in Montgomery and Schenectady County, New York to a high of $99 \%$ in Williamsburg County, South Carolina (Fig. 3). Because the sample size of casualty-producing tornado occurrence in many U.S. counties is small, only those counties impacted by multiple $(>1)$ casualty-producing tornadoes (677 total counties) are considered to gain insight into casualty rates that are more likely to

explain potential patterns in the distribution of casualties. Of the group of counties with 
Figure 2: (A) Per-housing unit state-level casualty rates for the contiguous United States, and (B) perhousing unit state-level casualty rates for states with 10 or more casualty-producing tornadoes. The casualty rates exist as the number of casualties per housing unit.

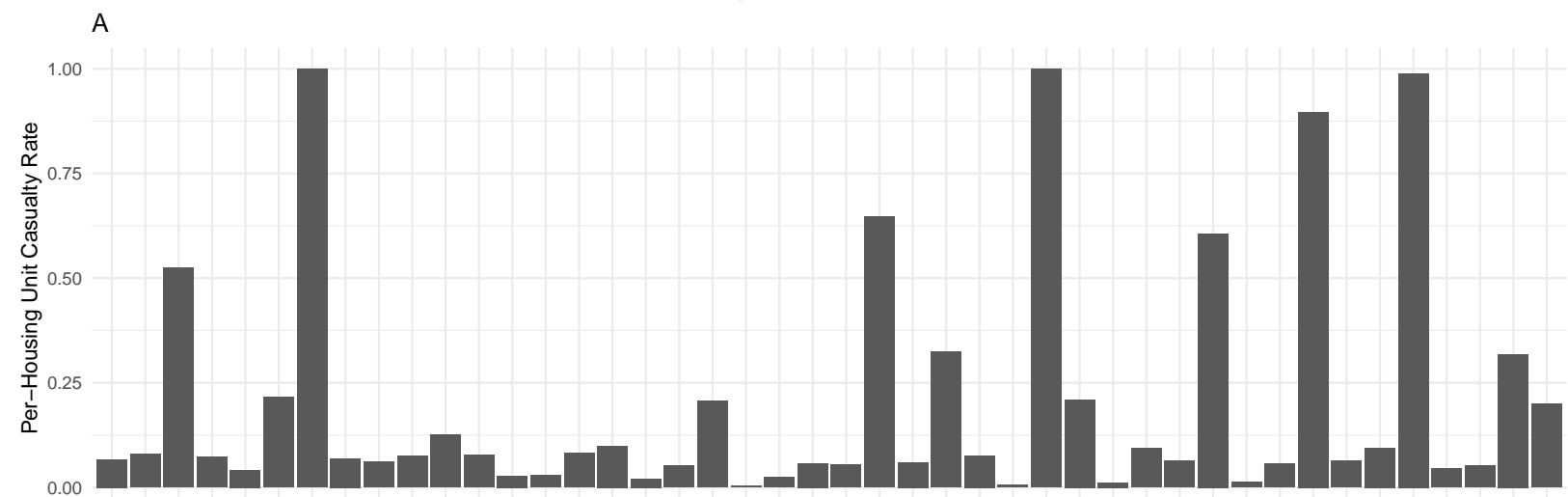

AL AR AZ CA CO CT DE FL GA IA ID IL IN KS KY LA MA MD ME MI MN MO MS MT NC ND NE NH NJ NM NY OH OK OR PA SC SD TN TX UT VA WI WV WY State

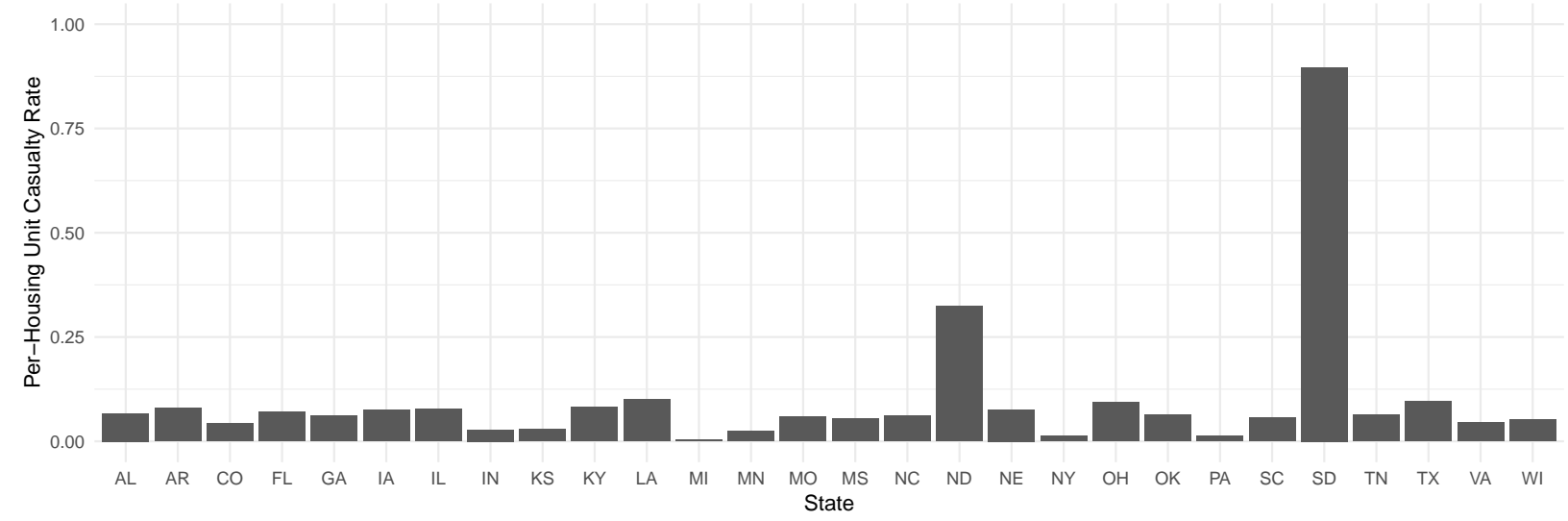

multiple casualty-producing tornadoes, per-capita casualty rates range from a low of $.02 \%$ in St. Charles County, Missouri to a high of $74 \%$ in Little River County, Arkansas (Fig. 3).

County-level per-capita injury and fatality rates are similar to county-level casualty rates. For the set of casualty-producing tornadoes, the per-capita fatality rate by county ranges from a low of 0 in over half $(55 \%)$ of the counties to a high of $80 \%$ in Beaver County, Oklahoma and Lipscomb County, Texas. The per-capita injury rate by county ranges from a low of $0 \%$ in 28 counties to a high of $99 \%$ in Williamsburg County, South Carolina. For the group of counties impacted by multiple casualty-producing tornadoes, per-capita fatality rates drop to a high of $18 \%$ in Evangeline Parish, Louisiana, while per-capita injury rates drop to a high of $68 \%$ in Little River County, Arkansas.

When the same set of all casualty-producing tornadoes subset by county is considered (1401 total counties), per-housing unit casualty rates range from a low of $.03 \%$ in Montgomery and Schenectady County, New York to a high of 100\% in 84 counties (Fig. 4). These county-level per-housing unit casualty rates change to a low of .06\% in St. Charles County, Missouri and a high of $100 \%$ in 14 counties when subset by counties impacted by multiple casualty-producing tornadoes (677 total counties) (Fig. 4). County-level per-housing unit 
Figure 3: (A) Per-capita county-level casualty rates for the contiguous United States, and (B) per-capita county-level casualty rates for counties with multiple casualty-producing tornadoes. The casualty rates exist as the number of casualties per person.
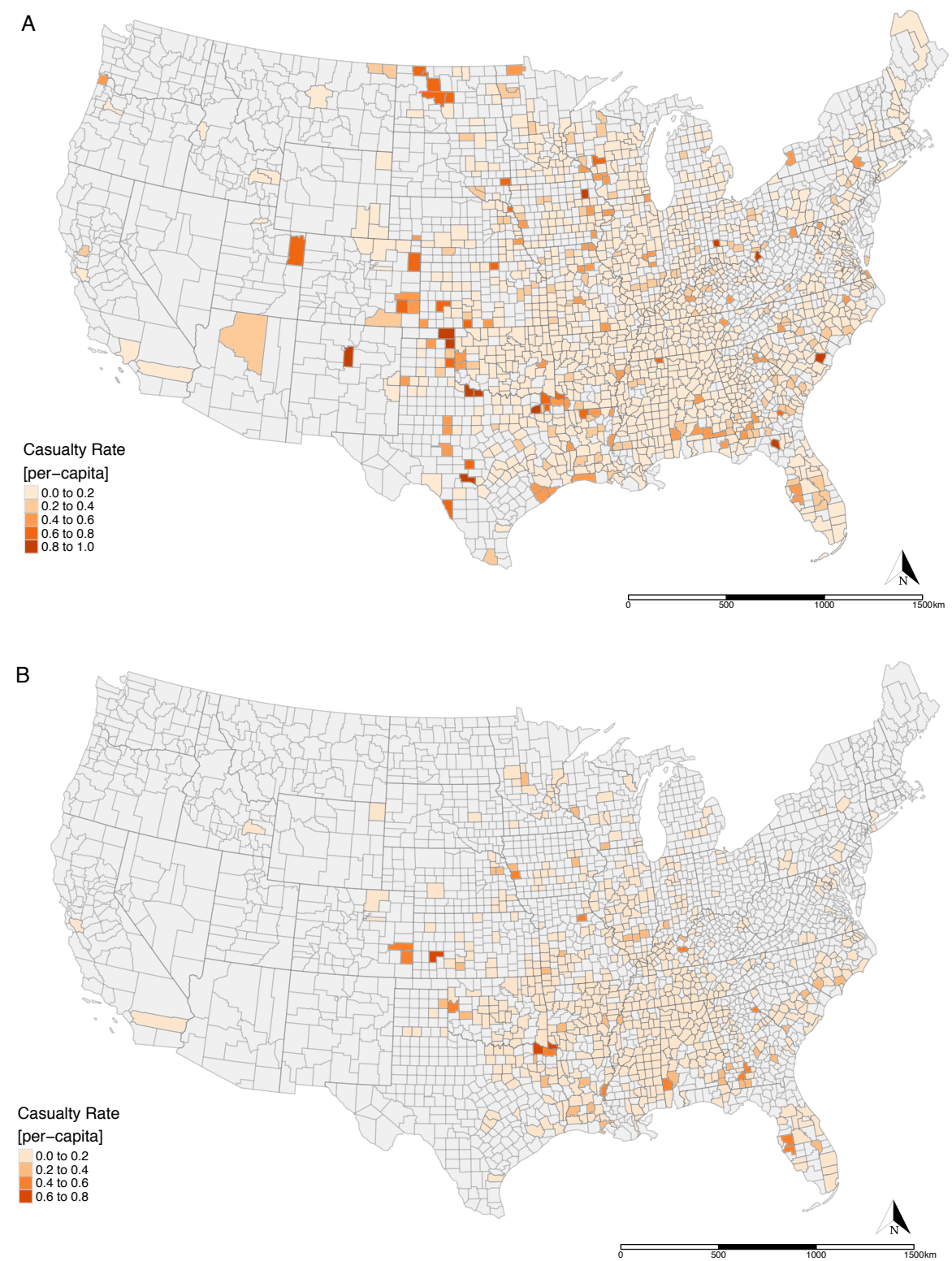
fatality rates range from a low of $0 \%$ in the same 55 counties mentioned above to a high of 100\% in Beaver County, Oklahoma, and Lipscomb County and Maverick County, Texas. County-level injury rates range from a low of $0 \%$ in 28 counties to a high of $100 \%$ in 78 counties. For the group of counties impacted by multiple county-producing tornadoes, the per-housing unit fatality rate drops to a high of $47 \%$ in Evangeline Parish, Louisiana and the per-housing unit injury rate remains at a high of $100 \%$, but only for 11 counties.

As was seen in the relationship between per-capita and per-housing unit casualty rates at the state-level, county-level casualty rates are higher, on average, at the per-housing unit level than at the per-capita level. The reason for this is again likely due to the relationship between population and housing units across rural counties of the U.S. - where older individuals live in aging and low quality housing - and the fact that, on average, casualty-producing tornadoes at the county-level impact more people than housing units.

\subsection{Tornado-Level Casualty Rates}

With a data set similar in structure to the SPC database - where tornado reports exist as separate rows - it is possible to analyze casualty rates at the individual tornado level. Thus, the data set can be thought of as a group of case studies for tornado casualty events. Important for this work is the ability to compare and contrast casualty rates across a number of casualty-producing tornadoes that impact a number of different areas with different underlying populations.

When evaluated at the individual tornado level, it is clear that using high profile casualty events as a basis for future casualty scenarios can become problematic. In fact, the most high profile casualty events (i.e. top 10 casualty-producing tornadoes) over the past two decades have estimated per-capita casualty rates that range from a low of 3\% (3 May, 1999 Oklahoma City (Moore), Oklahoma EF5 tornado) to a high of 48\% (22 May, 2011 Joplin, Missouri EF5 tornado) and estimated per-housing unit casualty rates that range from a low of 8\% (3 May, 1999 Oklahoma City (Moore), Oklahoma EF5 tornado) to a high of 27\% (26 December, 2015 Garland-Rowlett, Texas EF4 tornado).

Limitations in using case studies as the foundation for tornado casualty prediction can be seen in the differences in casualty patterns within individual events. For example, the 26 December, 2015 Garland-Rowlett, Texas EF4 tornado, which resulted in 478 casualties (10 fatalities and 468 injuries), had a per-capita casualty rate of $9.9 \%$ and a per-housing unit casualty rate of $27 \%$. These rates are significantly different than the 17 November, 2013 Washington, Illinois EF4 tornado, which resulted in 128 casualties (3 fatalities and 125 injuries), and had a per-capita casualty rate of $3.4 \%$ and a per-housing unit casualty rate of $8.1 \%$.

Of the ten case studies analyzed in this work, the per-capita casualty rates range from a low of $1 \%$ in the 1 June, 2011 Springfield, Massachusetts EF3 tornado to a high of $100 \%$ in the 30 May, 1998 Spencer, South Dakota EF4 tornado (Table 5). The per-housing unit casualty rates range from a low of $2.3 \%$ in the 14 March, 2008 Atlanta, Georgia EF2 tornado-and the aforementioned 2011 Springfield, Massachusetts EF3 tornado - to a high of 100\% in the 30 May, 1998 Spencer, South Dakota EF4 tornado (Table 5). Thus, while the use of case studies can aid in the production of knowledge about specific tornado casualty events, the use of case studies to predict what will happen, on average, in a casualty-producing tornado 
Figure 4: (A) Per-housing unit county-level casualty rates for the contiguous United States, and (B) perhousing unit county-level casualty rates for counties with multiple casualty-producing tornadoes. The casualty rates exist as the number of casualties per housing unit.
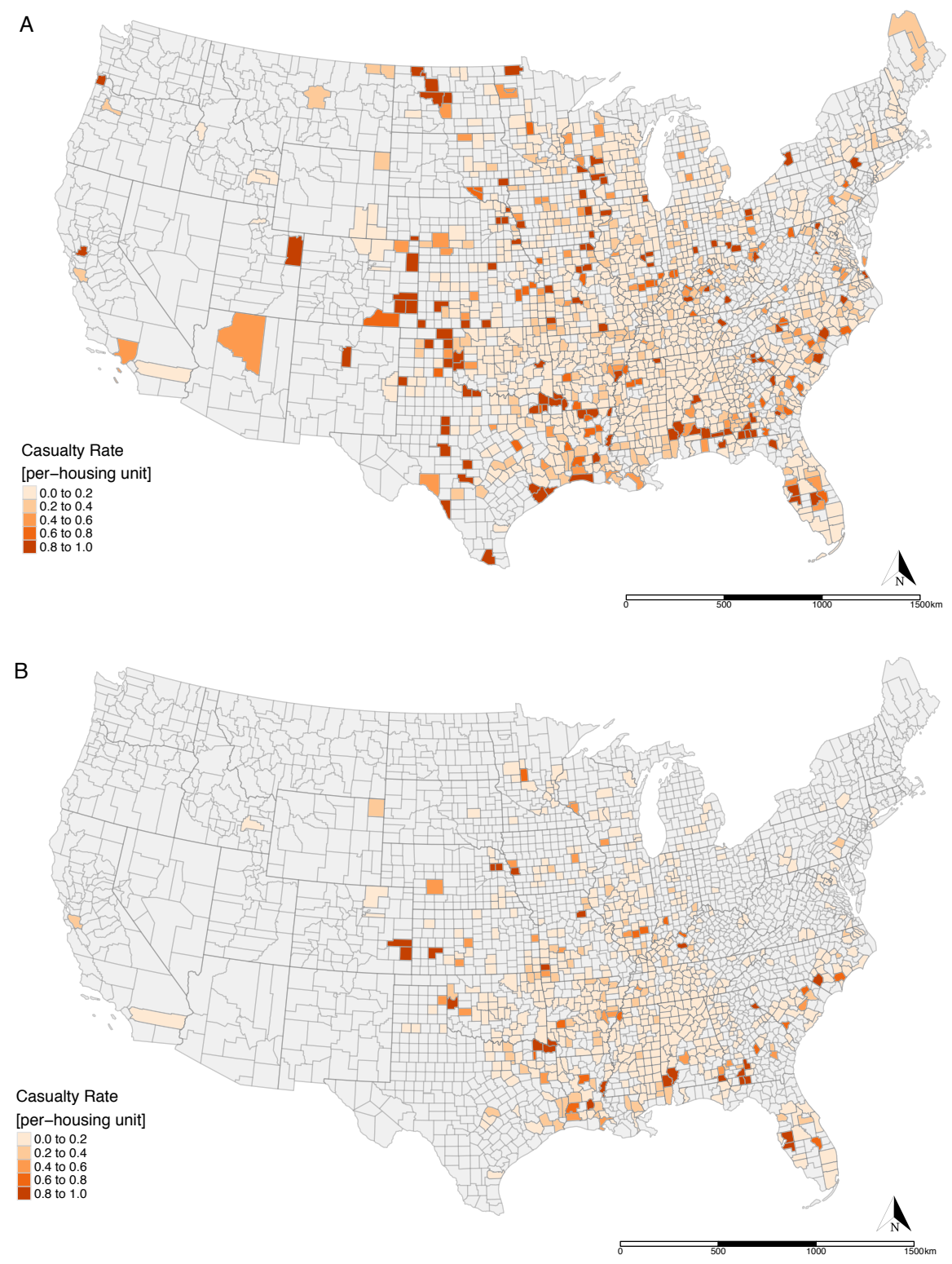
can result in large overpredictions and underpredictions without a deeper understanding of the potentially impacted area.

Table 5: Individual tornado casualty events and their associated casualty rates ranked by the number of casualties.

\begin{tabular}{lcccc}
\hline Tornado & Date (Day-Month-Year) & Casualties & Per-Capita & Per-Housing Unit \\
\hline Tuscaloosa-Birmingham, AL & $27-04-2011$ & 1664 & .0606 & .1256 \\
Moore, OK & $03-05-1999$ & 619 & .0323 & .0750 \\
Garland-Rowlett, TX & $26-12-2015$ & 478 & .0988 & .2728 \\
Evansville, IN & $06-11-2005$ & 262 & .0776 & .1853 \\
Springfield, MA & $01-06-2011$ & 203 & .0099 & .0232 \\
Spencer, SD & $30-05-1998$ & 156 & 1 & 1 \\
Washington, IL & $17-11-2013$ & 128 & .0334 & .0808 \\
Blue Ash, OH & $09-04-1999$ & 69 & .0420 & .1111 \\
Atlanta, GA & $14-03-2008$ & 31 & .0138 & .0234 \\
Ladysmith, WI & $02-09-2002$ & 27 & .0679 & .1547 \\
\hline
\end{tabular}

\section{Discussion}

Predicting future tornado impacts on society is a difficult endeavor. It relies on an understanding of connections between tornadoes and a changing climate, as well as connections between tornadoes and a changing population. Recent studies find upward trends in the interannual variability and clustering of tornadoes over the past few decades (Brooks et al., 2014; Elsner et al., 2015; Tippett et al., 2015). They also find a shift in the areal extent of tornado occurrence (Agee et al., 2016; Moore, 2017), and increasing tornado power (Elsner et al., 2018b). Other research argues that an increase in total population and dispersal of the built environment will lead to an increase in the amount of tornado destruction (Strader et al., 2017).

What impacts the relationship between tornadoes, climate, and society will have on humans - in the form of casualties - remains an open and challenging question. This is, in part, due to a lack of research that aims to understand tornado casualties as a global measure, rather than independent or case-study events. In response, here casualty rates are estimated for all casualty-producing tornadoes over the past several decades. These rates exist across multiple temporal and spatial scales and provide a foundation for the prediction of tornado casualties across the United States. For example, with a 22-year per-capita casualty rate of $2.3 \%$, a tornado impacting a community of 5,000 people would, on average, result in a casualty count of 115 people. That number can be broken down further into fatality and injury estimates of 8 and 107 people, respectively.

The utility of these casualty rates can also be seen in their flexibility to help predict casualty numbers based on tornado characteristics. For instance, because tornado reports include information on the magnitude of the associated damage (EF Scale), these casualty rates can be estimated for each EF-rating. This means that prediction of impacts can exist across damage thresholds. In practice, for the same community of 5,000 people, an EF5 tornado would, on average, result in 240 casualties with 31 fatalities and 209 injuries, while an EF2 tornado would, on average, result in 76 casualties with 4 fatalities and 72 injuries. 
Having the spatial extent of tornado damage paths allows for an understanding of tornado casualty rates across political boundaries (e.g. state-level and county-level). While state-level casualty rates may not be overly useful for specific events - a tornado impacting southern Alabama will affect different communities and different people than a tornado impacting northern Alabama - it does provide broad-scale knowledge of place-based human vulnerability. More useful, however, may be casualty rates at the county-level. For example, based on historical tornado reports and Census estimates, a community in Mitchell County, Georgia is likely to have more casualties than a community in Fulton County, Georgia at the per-capita level. In fact, a 200 person community in Mitchell County impacted by a casualty-producing tornado would result, on average, in 99 casualties, while a 200 person community in Fulton County impacted by a casualty-producing tornado would result, on average, in 1 casualty.

Another way to think about casualty rates, beyond a per-capita measurement, is at the housing unit level. The use of housing units as a damage statistic is not new (Ashley et al., 2014) and the quality of housing in an area is likely to impact the number of tornado casualties. Thus, a per-housing unit casualty rate may be useful to development planners and present a proxy for inadequate housing in communities across the country. With a 22-year per-housing unit casualty rate of 5.4\%, a 1,000 housing unit community impacted by a casualty-producing tornado would, on average, result in 271 casualties. Of these 271 casualties, 18 would, on average, be fatalities with the other 253 being injuries. Over the study period, the average number of total housing units impacted by casualty-producing tornadoes is 218 , which corresponds to 12 casualties, of which 1 is likely to be a fatality and 11 are likely to be injuries.

At the state- and county-level, both per-capita and per-housing unit casualty rates are higher for states and counties with larger rural communities than those states and counties with larger urban communities. When subset by Rural-Urban Continuum Codes and Office of Management and Budget metro and nonmetro categories, the per-capita casualty rate for rural communities is $3.2 \%$, while the per-capita casualty rate for urban communities is $1.6 \%$. Similarly, the per-housing unit casualty rate for rural communities is $7.3 \%$, while the perhousing unit casualty rate for urban communities is $3.9 \%$. This is likely responsible for the high casualty rates - relative to other states - consistently found in North Dakota and South Dakota, which both have extremely high rural populations of $40 \%$ and $43 \%$, respectively.

The reason for such a contrast in casualty rates between rural and urban communities may be due to differences in the types of relationships that exist in these areas (Donner, 2007), or due to low population and housing unit numbers in addition to older populations and poorquality housing. Regardless of the reasons behind an increased casualty rate, it is important to identify that rural communities are at a higher risk for casualties than others. For example, at the per-capita level, there is a hotspot of high casualty rates in the Ark-La-Tex region. If a casualty-producing tornado impacts a rural community of 200 people in Red River County, Texas, or Little River County, Arkansas the expected casualty rates are between 120-150 people. Conversely, if a casualty-producing tornado impacts an urban community is Dallas County, Texas, or Pulaski, Arkansas, the expected casualty rates are between 4-10 people. In addition, at the housing-unit level a large swath of high casualty rates exists across counties in southern Georgia and southern Alabama. If a casualty-producing tornado impacts a rural community of 100 housing units in Grady, Mitchell, Thomas, or Worth County, Georgia, 
the expected casualty rates are between 37-47 people. Conversely, if a casualty-producing tornado impacts an urban community of 100 housing units in Dekalb, Fulton, of Gwinnett County, Georgia, the expected casualty rates are between $0-1$ person.

As tornado behavior - and social structures and orgnization - continues to evolve, so too must our understanding of the societal impacts of these phenomena. While having estimates of future tornado damage (e.g. the number of housing units or total property loss) is important, having estimates of the number or rate of tornado casualties is equally as important. If tornado occurrence is relatively shifting to the East-Southeast and tornado outbreaks are becoming more concentrated (Gensini and Brooks, 2018; Moore and McGuire, 2019) with increased power, then leveraging this information for more accurate estimates of tornado casualties has the potential to spark mitigation strategies or educational outreach programs that can save lives.

\section{Summary}

Previous research has used statistical methods, most notably Monte Carlo simulations, to estimate the impact future tornadoes can have on society. It has also looked toward case studies to make sense of the number or rate of tornado injuries and fatalities. Here, general casualty rates are explored for all casualty-producing tornadoes over the period 1995-2016.

Through the use of a dasymetric procedure to gain tornado-level information, 22-year casualty rates are explored at the per-capita and per-housing unit level. Results show a per-capita casualty rate of $2.3 \%$ over the period with a per-capita fatality rate of $.15 \%$ and a per-capita injury rate of $2.1 \%$ over the time period. In addition, results show a per-housing unit casualty rate of $5.4 \%$ with a per-housing unit fatality rate of $.36 \%$ and a per-housing unit injury rate of $5.1 \%$ over the same study period.

Casualty rates increase with EF-rating with one exception: EF0 tornadoes have a higher casualty and injury rate than every other maximum damage rating. This is likely due to a combination of a small number problem, as EF0 tornadoes impact much smaller populations and total housing units than any other category, and the use of EF0 as an unknown rating. When subset by EF-rating, per-capita tornado casualty rates - excluding EF0 rates - range from a low of 1.5\% (EF1 and EF2) to a high of 4.8\% (EF5). At the per-housing unit level, tornado casualty rates - excluding EF0 rates - range from a low of 3.3\% (EF1) to a high of $12 \%(\mathrm{EF} 5)$.

Spatially, tornado casualty rates at both the per-capita and per-housing unit level are higher for states and counties with larger rural populations than those with smaller rural populations. For the set of states impacted by 10 or more casualty-producing tornadoes, percapita casualty rates range from a low of .15\% in Michigan to a high of $38 \%$ in South Dakota. For the same set of states, the per-housing unit casualty rates range from a low of .38\% in Michigan to a high of $90 \%$ in South Dakota. Additionally, for the set of counties impacted by multiple casualty-producing tornadoes, the per-capita casualty rates range from a low of $.02 \%$ in St. Charles County, Missouri to a high of $74 \%$ in Little River County, Arkansas. For the same set of counties, the per-housing unit casualty rates range from a low of .06\% in St. Charles County, Missouri to a high of $100 \%$ in 14 counties across Alabama, Arkansas, Georgia, Iowa, Kansas, Louisiana, Missouri, Florida, and Texas. 
Specific characteristics (e.g. EF-rating and spatial location) were analyzed in more detail to provide different choices to estimate future casualty scenarios in communities across the country. While this work focused on providing a foundation for casualty prediction, the method to estimate casualty rates allows for the creation of other research questions related to tornado casualties and their association with tornado behavior. For example, future work could evaluate differences in the rate of tornado casualties between daytime and nocturnal tornadoes or differences in the rate of tornado casualties at the seasonal-monthly-level. In addition, it is important to note that when predicting future casualty scenarios there are a number of other factors (e.g. mobile home density, housing quality, etc.) that can be evaluated in the context of tornado casualties over a longer period of record-tornado reports date back to 1950 - which may result in better interpretation of differences across space and time.

Ultimately, these per-capita and per-housing unit casualty rates are provided to improve the current prediction of tornado casualties. The hope is that emergency managers, meteorologists, and planners can use these rates to better prepare for tornado casualty events in their local communities. To that end, by expressing casualty rates across temporal and spatial scales, this work gives public officials multiple ways to better understand their community's human vulnerability and develop mitigation strategies or educational outreach programs that can reduce the loss of life and property.

\section{References}

Agee, E., Larson, J., Childs, S., Marmo, A., Aug. 2016. Spatial redistribution of u.s. tornado activity between 1954 and 2013. Journal of Applied Meteorology and Climatology 55 (8), 1681-1697.

URL https://doi.org/10.1175/jamc-d-15-0342.1

Antonescu, B., Fairman, J. G., Schultz, D. M., Apr. 2018. What is the Worst That Could Happen? Reexamining the 24-25 June 1967 Tornado Outbreak over Western Europe. Weather, Climate, and Society 10 (2), 323-340.

URL https://doi.org/10.1175/wcas-d-17-0076.1

Ashley, W., 2007. Spatial and temporal analysis of tornado fatalities in the United States: 1880-2005. Weather and Forecasting 22, 1214-1228.

Ashley, W. S., Strader, S., Rosencrants, T., Krmenec, A. J., apr 2014. Spatiotemporal changes in tornado hazard exposure: The case of the expanding bull's-eye effect in chicago, illinois. Wea. Climate Soc. 6 (2), 175-193.

URL http://dx.doi.org/10.1175/WCAS-D-13-00047.1

Bazuin, J. T., Fraser, J. C., dec 2013. How the ACS gets it wrong: The story of the american community survey and a small, inner city neighborhood. Applied Geography 45, 292-302. URL https://doi.org/10.1016/j.apgeog.2013.08.013

Brooks, H. E., Carbin, G. W., Marsh, P. T., oct 2014. Increased variability of tornado occurrence in the united states. Science 346 (6207), 349-352.

URL https://doi.org/10.1126\%2Fscience. 1257460 
Brooks, H. E., Doswell, C. A., 2002. Deaths in the 3 May 1999 Oklahoma City tornado from a historical perspective. Weather and Forecasting 17, 354-361.

Brooks, H. E., Doswell, C. A., Sutter, D., Jan. 2008. Reply. Bulletin of the American Meteorological Society 89 (1), 87-90.

URL https://doi.org/10.1175/bams-89-1-87

Brown, S., Archer, P., Kruger, E., Mallonee, S., 2002. Tornado-Related Deaths and Injuries in Oklahoma due to the 3 May 1999 Tornadoes. Weather and Forecasting 17, 343-353.

Clarke, L., Jan. 2005. Worst-Case Thinking. Natural Hazards Observer 29 (3). URL https://hazards.colorado.edu/uploads/observer/2005/jan05/jan05.pdf

Corfidi, S. F., Weiss, S. J., Kain, J. S., Corfidi, S. J., Rabin, R. M., Levit, J. J., Apr. 2010. Revisiting the 3-4 april 1974 super outbreak of tornadoes. Weather and Forecasting 25 (2), $465-510$.

URL https://doi.org/10.1175/2009waf2222297.1

Cutter, S. L., Mitchell, J. T., Scott, M. S., dec 2000. Revealing the vulnerability of people and places: A case study of georgetown county, south carolina. Annals of the Association of American Geographers 90 (4), 713-737.

URL https://doi.org/10.1111\%2F0004-5608.00219

Daley, W. R., Brown, S., Archer, P., Kruger, E., Jordan, F., Batts, D., Mallonee, S., Jun. 2005. Risk of Tornado-related Death and Injury in Oklahoma, May 3, 1999. American Journal of Epidemiology 161 (12), 1144-1150.

URL https://doi.org/10.1093/aje/kwi142

Daneshvaran, S., Morden, R. E., 2007. Tornado risk analysis in the United States. Journal of Risk Finance 8 (2), 97-111.

URL https://www.emerald.com/insight/content/doi/10.1108/ $15265940710732314 / \mathrm{full} / \mathrm{html}$

Dixon, R. W., Moore, T. W., 2012. Tornado vulnerability in Texas. Weather, Climate, and Society 4, 59-68.

Donner, W. R., 2007. The political ecology of disaster: An analysis of factors influencing u.s. tornado fatalities and injuries, 1998-2000. Demography 44 (3), 669-685.

URL https://doi.org/10.1353\%2Fdem.2007.0024

Donner, W. R., Rodriguez, H., Diaz, W., jan 2012. Tornado warnings in three southern states: A qualitative analysis of public response patterns. Journal of Homeland Security and Emergency Management 9 (2).

URL https://doi.org/10.1515/1547-7355.1955

Doswell, C. A., Brooks, H. E., Dotzek, N., 2009. On the implementation of the enhanced Fujita scale in the USA. Atmos. Res. 93, 554-563. 
Eidson, M., Lybarger, J. A., Parsons, J. E., Maccormack, J. N., Freeman, J. I., 1990. Risk factors for tornado injuries. International Journal of Epidemiology 19 (4), 1051-1056. URL https://doi.org/10.1093/ije/19.4.1051

Elsner, J. B., Elsner, S. C., Jagger, T. H., 2015. The increasing efficiency of tornado days in the United States. Climate Dynamics 45 (3-4), 651-659.

Elsner, J. B., Fricker, T., Berry, W. D., jul 2018a. A model for u.s. tornado casualties involving interaction between damage path estimates of population density and energy dissipation. Journal of Applied Meteorology and Climatology.

URL https://doi.org/10.1175/jamc-d-18-0106.1

Elsner, J. B., Fricker, T., Schroder, Z., dec 2018b. Increasingly powerful tornadoes in the united states. Geophysical Research Letters.

URL https://doi.org/10.1029/2018gl080819

Elsner, J. B., Ryan, E., Strode, G., Apr. 2018c. Structural property losses from tornadoes in florida. Weather, Climate, and Society 10 (2), 253-258.

URL https://doi.org/10.1175/wcas-d-17-0055.1

Fan, F., Pang, W., Mar. 2019. Stochastic track model for tornado risk assessment in the u.s. Frontiers in Built Environment 5.

URL https://doi.org/10.3389/fbuil.2019.00037

Folch, D. C., Arribas-Bel, D., Koschinsky, J., Spielman, S. E., aug 2016. Spatial variation in the quality of american community survey estimates. Demography 53 (5), 1535-1554.

URL https://doi.org/10.1007/s13524-016-0499-1

Fricker, T., 2020. Tornado-level estimates of socioeconomic and demographic variables. Natural Hazards Review, Forthcoming.

Fricker, T., Elsner, J. B., 2015. Kinetic energy of tornadoes in the United States. PLoSONE 10, e0131090.

Fricker, T., Elsner, J. B., Camp, P., Jagger, T. H., 2014. Empirical estimates of kinetic energy from some recent U.S. tornadoes. Geophysical Research Letters 41, 4340-4346.

Fricker, T., Elsner, J. B., Jagger, T. H., 2017a. Population and energy elasticity of tornado casualties. Geophysical Research Letters 44, 3941-3949.

URL https://doi.org/10.1002\\%2F2017g1073093

Fricker, T., Elsner, J. B., Mesev, V., Jagger, T. H., oct 2017b. A dasymetric method to spatially apportion tornado casualty counts. Geomatics, Natural Hazards and Risk 8 (2), $1768-1782$.

URL https://doi.org/10.1080/19475705.2017.1386724

Gensini, V. A., Brooks, H. E., Oct. 2018. Spatial trends in united states tornado frequency. npj Climate and Atmospheric Science 1 (1).

URL https://doi .org/10.1038/s41612-018-0048-2 
Grazulis, T. P., 1990. Significant Tornadoes, 1880-1989: Discussion and analysis. Significant Tornadoes, 1880-1989. Environmental Films.

URL http://books .google.com/books?id=E8hFAAAAYAAJ

Hall, S. G., Ashley, W. S., Nov. 2008. Effects of urban sprawl on the vulnerability to a significant tornado impact in northeastern illinois. Natural Hazards Review 9 (4), 209 219.

URL https ://doi.org/10.1061/(asce) 1527-6988(2008) 9:4(209)

Hammer, B. O., Schmidlin, T. W., Jan. 2000. Vehicle-occupant deaths caused by tornadoes in the united states, 1900-1998. Environmental Hazards 2 (3), 105-118.

URL https://doi.org/10.3763/ehaz.2000.0215

Kilijanek, T., Drabek, T., 1979. Assessing long-term impacts of a natural disaster: A focus on the elderly. Gerontologist 19, 555-566.

Kuligowski, E. D., Lombardo, F. T., Phan, L. T., Levitan, M. L., Jorgensen, D. P., March 2013. Draft Report, National Institute of Standards and Technology (NIST) Technical Investigation of the May 22, 2011, Tornado in Joplin, Missouri. Tech. Rep. NIST NCSTAR - 3, NIST.

Legates, D. R., Biddle, M. D., 1999. Warning response and risk behavior in the Oak Grove Birmingham, Alabama, tornado of 08 April 1998. Natural Hazards Center Quick Response Report 116.

Lim, J., Loveridge, S., Shupp, R., Skidmore, M., jul 2017. Double danger in the double wide: Dimensions of poverty, housing quality and tornado impacts. Regional Science and Urban Economics 65, 1-15.

URL https://doi.org/10.1016/j.regsciurbeco.2017.04.003

Macdonald, H., dec 2006. The american community survey: Warmer (more current), but fuzzier (less precise) than the decennial census. Journal of the American Planning Association 72 (4), 491-503.

URL https://doi.org/10.1080/01944360608976768

Meyer, C. L., Brooks, H. E., Kay, M. P., 2002. A hazard model for tornado occurrence in the United States. In: 13th Symposium on Global Change and Climate Variations.

Moore, T. W., Sep. 2017. Annual and seasonal tornado trends in the contiguous united states and its regions. International Journal of Climatology 38 (3), 1582-1594.

URL https://doi.org/10.1002/joc.5285

Moore, T. W., McGuire, M. P., Jul. 2019. Using the standard deviational ellipse to document changes to the spatial dispersion of seasonal tornado activity in the united states. npj Climate and Atmospheric Science 2 (1).

URL https://doi.org/10.1038/s41612-019-0078-4 
National Oceanic and Atmospheric Administration, 2015. National Weather Service Weather Fatality, Injury, and Damage Statistics.

URL \{http://www.nws.noaa.gov/om/hazstats/resources/weather \_fatalities. pdf\}

Salvo, J. J., Lobo, A. P., oct 2006. Moving from a decennial census to a continuous measurement survey: factors affecting nonresponse at the neighborhood level. Population Research and Policy Review 25 (3), 225-241.

URL https://doi.org/10.1007/s11113-006-0008-0

Simmons, K. M., Sutter, D., jun 2005. WSR-88D radar, tornado warnings, and tornado casualties. Weather and Forecasting 20 (3), 301-310.

URL https://doi.org/10.1175\%2Fwaf 857.1

Simmons, K. M., Sutter, D., apr 2008. Tornado warnings, lead times, and tornado casualties: An empirical investigation. Weather and Forecasting 23 (2), 246-258.

URL https://doi.org/10.1175\%2F2007waf2006027.1

Simmons, K. M., Sutter, D., oct 2009. False alarms, tornado warnings, and tornado casualties. Weather, Climate, and Society 1 (1), 38-53.

URL https://doi.org/10.1175\%2F2009wcas 1005.1

Spielman, S. E., Folch, D., Nagle, N., jan 2014. Patterns and causes of uncertainty in the american community survey. Applied Geography 46, 147-157.

URL https://doi.org/10.1016/j.apgeog.2013.11.002

Strader, S. M., Ashley, W. S., oct 2018. Finescale assessment of mobile home tornado vulnerability in the central and southeast united states. Weather, Climate, and Society 10 (4), 797-812.

URL https://doi.org/10.1175/wcas-d-18-0060.1

Strader, S. M., Ashley, W. S., Pingel, T. J., Krmenec, A. J., jan 2017. Projected 21st century changes in tornado exposure, risk, and disaster potential. Climatic Change 141 (2), 301313.

URL https://doi.org/10.1007\%2Fs10584-017-1905-4

Tippett, M. K., Allen, J. T., Gensini, V. A., Brooks, H. E., feb 2015. Climate and hazardous convective weather. Current Climate Change Reports 1 (2), 60-73.

URL http://dx.doi.org/10.1007/s40641-015-0006-6

Verbout, S. M., Brooks, H. E., Leslie, L. M., Schultz, D. M., 2006. Evolution of the U.S. tornado database: 1954-2003. Weather and Forecasting 21, 86-93.

Wurman, J., Robinson, P., Alexander, C., Richardson, Y., jan 2007. Low-level winds in tornadoes and potential catastrophic tornado impacts in urban areas. Bulletin of the American Meteorological Society 88 (1), 31-46.

URL https://doi .org/10.1175\%2Fbams-88-1-31 